\title{
Ensino via Pesquisa: a universidade para a diversidade latino-americana
}

Ivani Ferreira de Faria (UFAM)

Karina Mendes Thomaz (UFSC)

\section{Resumo}

Para se repensar a universidade frente à diversidade cultural e linguística presente nos países latino-americanos, é preciso considerar, não apenas os casos intra-nacionais, mas também a diversidade entre os próprios países. Esse imperativo surge a partir do estabelecimento de politicas mercosulistas de integração voltadas para a área educacional, que abrangem tanto a Educação Básica quanto a Educação Superior. Assim, o Projeto Escolas Interculturais Bilingues de Fronteira do MERCOSUL (PEIBF) e os blocos temáticos do Setor Educacional do MERCOSUL para a Educação Superior, a saber, Reconhecimento, Mobilidade e Cooperação Inter-institucional, apresentam-se como instigadores de reflexões sobre como abarcar nas salas de aula a diversidade latino-americana nas instituições educacionais dos países membros. Se o imperativo da reflexão está posto, a forma pela qual a Educação poderá trabalhar com e pela diversidade cultural e linguística latino-americana, tanto nos casos intra quanto inter-nacionais, ainda está sendo definida. Uma dessas formas é o Ensino via Pesquisa. Mas por que o Ensino via Pesquisa pode ser considerado um dos instrumentos para a resignificação da universidade e das escolas do século XXI inserindo-as em um marco de valorização da diversidade cultural e linguística? Objetivando responder a tal questão, o trabalho foi organizado de forma a apresentar o método "Ensino via Pesquisa" para, depois, apresentar dois contextos nos quais ele é adotado. Um desses contextos utiliza o Ensino via Pesquisa para a diversidade latino-americana intra-nacional, a dos povos originários. O outro contexto abrange a diversidade latino-americana inter-nacional, aquela existente entre os países do bloco.

Palavras-chave: Ensino via Pesquisa; Projeto Escolas Interculturais Bilíngues de Fronteira do MERCOSUL; Licenciatura Indígena; Diversidade Cultural e Linguística; Política Linguística. 


\section{O Ensino via Pesquisa}

“Toda pessoa tem direito à instrução", ou seja, a Declaração Universal dos Direitos Humanos define e defende a Educação enquanto direito. A Educação é sempre um direito? $\mathrm{O}$ acesso à Educação homogeneizadora dos grupos dominantes é um direito? Um direito que tolhe o também direito à diversidade cultural e linguística ainda pode ser considerado direito? Qual a fronteira entre o direito e o dever no que diz respeito ao acesso à Educação? Boaventura Santos (2007, p. 44) alerta de que "Tenemos el derecho de ser iguales cuando la diferencia nos inferioriza, tenemos el derecho de ser diferentes cuando la igualdade nos descaracteriza." Quando é importante ser diferente para manter o acesso à Educação enquanto um direito e não um dever?

Para que o acesso à Educação seja, de fato, um direito humano que não descaracterize nem inferiorize, é necessário, como pré-requisito a ele, a consciência do direito à diversidade cultural e linguística. A Interculturalidade, entendida como diálogo horizontal entre culturas e como alternativa ao monólogo vertical imposto pelos grupos dominantes, surge, assim, como solução para a ambiguidade conceitual presente no entendimento sobre o acesso à Educação ("direito ou dever?"). Mas como aplicar a Interculturalidade nas salas de aula dos diversos níveis educacionais?

O Ensino via Pesquisa (EvP), por partir da participação dos alunos na elaboração do plano de trabalho pela proposição por eles de problemáticas a serem investigadas, estimulando o diálogo horizontal entre professor e alunos, configura-se como um método de ensino no qual o princípio da Interculturalidade é exercido como praxe educacional.

A base do trabalho educacional no EvP é o desenvolvimento de pesquisas propostas pelos alunos em forma de problemáticas, o que permite a construção de um currículo que atenda às necessidades e especificidades culturais e linguísticas de cada grupo, não se atendo a fórmulas conteudísticas pré-definidas e, portanto, homogeneizadoras. O desenvolvimento de tais pesquisas é guiado pelo projeto de aprendizagem, elaborado após a formulação da problemática em forma de mapas conceituais, nos quais outras perguntas necessárias à resolução da problemática central são apresentadas pelos alunos. Como postula Gilvan Müller de Oliveira na primeira das Doze Questões Estruturantes para o Trabalho Pedagógico via Pesquisa, explicitadas no livro Interesse, Pesquisa e Ensino: uma equação para a Educação Escolar no Brasil,

A pesquisa se inicia, portanto, através da determinação - de forma dialógica - do quê os alunos gostariam de saber, de estudar, que problemáticas gostariam de atacar, que mistérios 
gostariam de desvendar. Começamos, portanto, recortando as problemáticas que vão conduzir os trabalhos por um determinado período de tempo, criando, nas discussões em pequenos grupos e em grande grupo, o objeto da pesquisa (OLIVEIRA, 2004, p.48).

A Interculturalidade é, portanto, no EvP, viabilizada pela descentralização do poder em sala de aula. Assim, se o professor não é mais o único detentor das verdades (conteúdos) a serem ensinadas, possibilita-se a audição de outras vozes no processo educacional. Segundo Gilvan Müller,

(...) a participação continuada nos processos de pesquisa alteram muito profundamente as relações entre professores e alunos. Em primeiro lugar, tira a absoluta centralidade da figura do professor, ou melhor: aquele tipo de centralidade que ele tem na escola disciplinar e conteudista. O processo é descentralizado: não é o professor (o único) que transmite conhecimento, mas a responsabilidade pela produção do conhecimento é de todos" (OLIVEIRA, 2004, p.55).

Quanto à ambiguidade do acesso à Educação, compreendido como direito humano ou como dever descaracterizador e inferiorizante, o Ensino via Pesquisa, ao tratar dos interesses dos grupos envolvidos, não ditando nem mesmo métodos de ensino a priori, atribui ao ensino a característica de direito humano; por um lado, por não impor a homogeneização cultural e linguística; por outro, por aceitar e legitimar a diversidade.

Na experiência da pesquisa, partimos do princípio de que cada um pode - e deve - expressar quais são seus interesses, e esses interesses não serão desprezados: não julgamos, assim, que alguns conhecimentos são 'da escola' e outros não são, que alguns são tratáveis e outros não são. A rígida definição do que é conhecimento escolar e do que não é, feita tradicionalmente pelo sistema escolar, tem amplas consequências sobre as problemáticas - e portanto os interesses - que excluímos da escola. Excluir da escola interesses significa excluir as próprias pessoas de quem esses interesses são expressão (OLIVEIRA, 2004, p.48).

Repensar a universidade e a Educação na(s) diversidade(s) latino-americana(s) requer, portanto, inseri-las em um marco de valorização da diversidade cultural e linguística do diversos grupos, oferecendo-lhes acesso a uma Educação que represente um direito humano e não um dever, o que é possibilitado pelo Ensino via Pesquisa.

A seguir, apresentar-se-á essa inserção, que vem ocorrendo na Licenciatura Indígena da Universidade Federal do Amazonas, em São Gabriel da Cachoeira. 


\section{Estudo de Caso: o Ensino via Pesquisa para a Diversidade Latino-Americana Intra-Nacional na Licenciatura Indígena da UFAM em São Gabriel da Cachoeira}

Exemplo de respeito à diversidade latino-americana intra-nacional, aquela existente dentro dos limites geopolíticos de cada país, o curso de Licenciatura Indígena em Políticas Educacionais e Desenvolvimento Sustentável, que a Universidade Federal do Amazonas (UFAM) oferece no município de São Gabriel da Cachoeira (Figura 1), alia o Ensino via Pesquisa a uma política linguística de valorização da diversidade existente entre os povos amazônicos.

Figura 1: Localização do município de São Gabriel da Cachoeira/AM

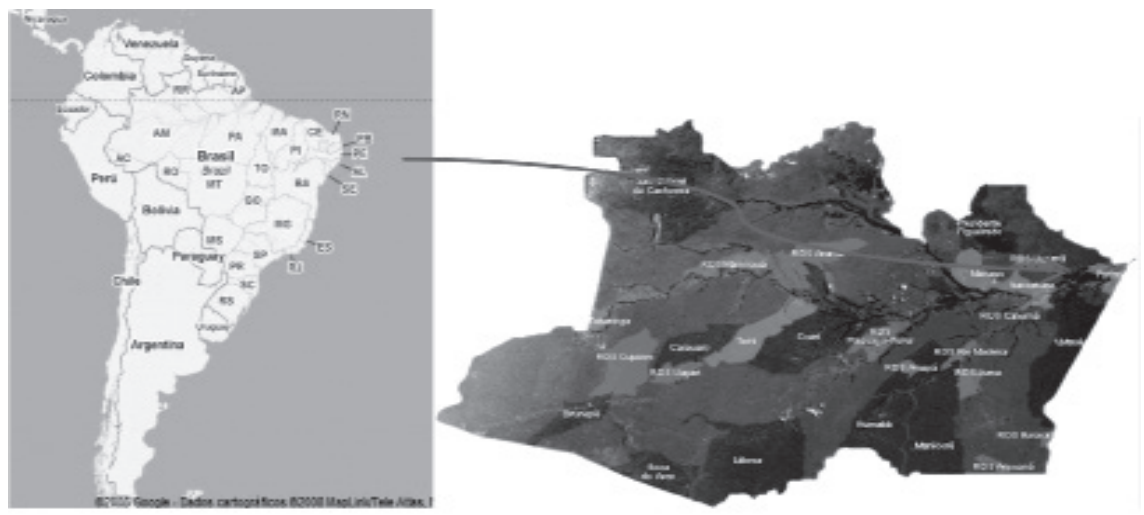

Fonte: http://gina.abc.org.br/publicacoes/ba/NABCUU16/index.html

O município brasileiro de São Gabriel da Cachoeira, localizado no noroeste do estado do Amazonas e sede da Licenciatura da UFAM, é altamente pluriétnico e multilíngue, característica que motivou a co-oficialização, ao lado da língua portuguesa, de três línguas indígenas, o Tukano, o Nheengatu e o Baniwa, no ano de 2002 , pela lei municipal $n^{\circ} 145 / 2002^{1}$, regulamentada pela Lei Municipal no. 210/2006. Essa política de co-oficialização e a diversidade linguística existente para além das línguas abarcadas por essa lei levaram à coordenação da Licenciatura da UFAM a organizar o curso em três pólos distintos, cada um correspondente a uma das três línguas co-oficializadas no município. Nesses pólos, a política linguística definida pela coordenação do curso em conjunto com as comunidades instituiu que as línguas de instrução são as línguas co-oficiais do município, auxiliadas pela língua portuguesa. As demais línguas indígenas presentes na região ocupam o status de línguas de trabalho durante o curso.

Essa política linguística estabelecida pelo curso, além de atender à legislação municipal sobre as línguas co-oficiais, garante

1 O texto da lei pode ser obtido em: http://www. ipol.org.br/imprimir. php?cod=83 também o uso efetivo da língua materna indígena em processos de aprendizagem, direito constitucional no Brasil segundo o artigo 210, parágrafo segundo. 
$\S 2^{\circ}$ - O ensino fundamental regular será ministrado em língua portuguesa, assegurada às comunidades indígenas também a utilização de suas línguas maternas e processos próprios de aprendizagem (BRASIL, 1988.)

A garantia ao uso da língua materna pela população indígena é posta em prática, na Licenciatura da UFAM, nas aulas ministradas pelo método do Ensino via Pesquisa, "baseado muito mais no aprendizado do aluno do que no ensino do professor", como afirma o Professor Gilvan Müller na proposta da Licenciatura da UFAM. Assim, ao centrar no aprendizado do aluno ao invés de no ensino do professor, o EvP permite que toda a discussão seja feita pelos alunos em língua indígena.

Além da valorização da diversidade linguística possibilitada pela política linguística do curso e pelo Ensino via Pesquisa, o método aplicado pela Licenciatura da UFAM também corresponde a um significativo instrumento para a valorização da diversidade cultural dos diversos grupos de alunos, devido à proposição por eles próprios das pesquisas que serão desenvolvidas e que, por isso, atendem ao interesse específico de cada grupo, trazendo para a sala de aula características culturais diversas.

Por exemplo, no mês de fevereiro de $2011^{2}$, o então diretor executivo do IILP - Instituto Internacional da Língua Portuguesa e coordenador do IPOL - Instituto de Investigação e Desenvolvimento em Política Linguística, Prof. Gilvan Müller de Oliveira, esteve nos distritos de Cucuí (onde funciona o Pólo Nheengatu) e de Taracuá (sede do Pólo Tukano), no município de São Gabriel da Cachoeira, a convite da UFAM, para trabalhar com os alunos, em sua maioria professores em escolas indígenas, problemáticas relacionadas ao uso da língua Nheengatu nas escolas indígenas nas diferentes comunidades e à definição da ortografia das línguas Tukano, Desano, Kotiria, Kubeo e Tuyuka.

Utilizando-se do EvP, o professor Gilvan finalizou cada uma das semanas de trabalhos em cada um dos pólos da Licenciatura com produtos concretos voltados para a comunidade.

No Pólo Nheengatu, em Cucuí, depois de uma semana de sistematização dos trabalhos de investigação realizados previamente pelos alunos/professores nas comunidades divididas em cinco regiões (São Gabriel da Cachoeira, Baixo Rio Negro, Médio e Alto Rio Negro, Baixo Içana e Alto Xié), na qual foram discutidas, de acordo com as necessidades apresentadas pelos alunos,

2 Essa experiência foi presenciada por mim, orientanda do professor Gilvan Müller de Oliveira, enquanto convidada da coordenadora Ivani Farias da Licenciatura da UFAM em São Gabriel da Cachoeira. questões como a definição do conceito de pesquisa, universo e amostragem da pesquisa, partes essenciais de um relatório de pesquisa, os alunos/professores apresentaram os resultados no I Seminário de Pesquisas em Nheengatu da UFAM (I Mukamesá Muraki Sikaisá Y $\square g a$ Y $\square$ gatu Rupî) no Clube Social de Cucuí, que contou também com um Mural Literário em Nheengatu. 
O Seminário, que entregou certificados de participação em nheengatu, representou a legitimidade da língua nheengatu como língua de instrução no município de São Gabriel da Cachoeira, despertando nos presentes discursos emocionados, como o do diretor da escola local, Carlos Sávio, e o da professora Maria Lúcia que, parabenizando as apresentações feitas, reivindicou: "A gente precisa valorizar mais a nossa língua". A presença da língua indígena na totalidade do evento, inclusive no discurso de abertura realizado pelo diretor executivo do IILP, Prof. Gilvan Müller, suscitou nas autoridades locais o desejo, expresso em compromisso, de aprendê-la. O subtenente Toledo, do $4^{\circ}$ Pelotão Especial de Fronteira, em português, desculpou-se por só saber duas palavras em nheengatu, Poranga pituna (Boa noite), e comprometeu- se a falar em nheengatu se no próximo ano houvesse outro evento daquele porte. O subtenente comentou ainda da "experiência maravilhosa" que está sendo para ele, oriundo do litoral do Nordeste brasileiro, ter contato com línguas novas, que ele não sabia que existia ainda no Brasil. O sub-prefeito do distrito de Cucuí iniciou a fala lamentando o fato de não saber falar em nheengatu, o que, segundo ele, era culpa dos pais que não o ensinaram. Citando o subtenente, o sub-prefeito afirmou que a partir dali começaria a estudar o nheengatu.

No distrito de Taracuá, onde funciona o Pólo Tukano da Licenciatura da UFAM, os trabalhos da semana culminaram em uma declaração sobre a unificação do alfabeto e diacríticos usados pela Língua Tukano. Esta declaração, redigida em Tukano e em português, em breve, estará disponível no site do curso e balizará toda a publicação feita em língua Tukano pelos alunos do Pólo, sendo, a partir de então, utilizada também nas escolas onde os alunos/professores atuam.

Ex-aluno do internato salesiano de Taracuá, prédio onde, hoje, são oferecidas as etapas intensivas da Licenciatura em Políticas Educacionais e Desenvolvimento Sustentável da UFAM para o Pólo Tukano, Max, como, amistosamente, é chamado Maximiliano Menezes, o representante da turma Tukano e atual vice-presidente da FOIRN - Federação das Organizações Indígenas do Rio Negro, expressou o valor histórico da retomada da valorização da diversidade linguística na região: "A história de a gente estar trabalhando na ortografia da língua Tukano, dos Desano, de outros povos que estão aqui nessa Licenciatura, me alegra muito isso, de ver novamente, aqui, nesse prédio salesiano que tanto obrigou a gente a deixar a nossa língua."

O destaque para o fato de a Licenciatura da UFAM ser ofertada no mesmo prédio onde funcionava a antiga escola salesiana, ressalta a diferença de objetivos entre os dois ensinos: um voltado para o respeito e promoção da diversidade linguística e cultural, outro para a homogeneização das culturas e das línguas. Max 
segue o depoimento refletindo sobre as consequências de um ensino vertical e homogeneizador.

Então, quando comecei a estudar aqui em Taracuá, aqui neste colégio, praticamente eu entrei entendendo algumas palavrinhas em português. Talvez nem dois por cento do que se falava eu entendia, custou para mim aprender, aliás, entender o português, não falar tão bem. Mas, assim, o ensino, tudo, era em português, e a gente não falava nem uma palavra em Tukano na sala de aula. Praticamente, talvez isso nos prejudicou para a vida adulta, porque a gente sempre sentou na sala de aula com medo de perguntar e errar o português na frente de outros colegas, embora que todos os colegas não sabiam também falar o português, mas era obrigado você falar o português com o professor. Passei praticamente desde o primeiro ano até a oitava série aqui, neste sistema de ensino, que você tem que falar em português na sala de aula, e por isso, muitas vezes, a gente perdia a oportunidade de também contribuir com os colegas, de também levantar e falar. A gente nunca teve a oportunidade de falar, de se levantar e falar... Acredito que qualquer um da minha época, quando saiu daqui, saiu com toda aquela timidez de levantar e falar na frente dos colegas, porque você tinha na sua mente que você teria algo errado de falar o português. (...) Ninguém nunca disse que nós poderíamos escrever na nossa língua. Ninguém nunca falou que nós poderíamos falar nas nossas línguas para a gente interagir em determinado tempo. Ninguém nunca nos disse "Não, vocês podem discutir da forma como vocês pensam para a gente ir direcionando para o objetivo, para o futuro do povo indígena do Rio Negro". Ninguém nunca falou isso! ${ }^{3}$.

Analisando as diferenças entre os dois ensinos ministrados no mesmo prédio, Max salienta a importância do Ensino via Pesquisa para a consciência da diversidade cultural e linguística da própria turma, que reflete a realidade da região.

Eu acho que assim: essa caminhada me traz aqui, nessa Licenciatura em Políticas Educacionais, uma nova realidade para mais um passo a mais, para a gente estar discutindo entre várias etnias que se encontram aqui uma troca de experiências, de conhecimento. Aqui, eu acho que, aqui, a gente começa a entender que somos realmente povos diferentes, que temos nossos mitos, nossas histórias, porque, até então, estava assim adormecida. Eu sempre falo essa palavra "adormecida", porque a gente não se manifestava nas nossas tradições culturais, a gente tinha no coração, porém, não era uma coisa manifestada, a língua, as nossas músicas, as nossas danças, embora sabendo, mantendo isso na consciência, a gente não

3 O depoimento completo pode ser lido na reportagem "A Língua Portuguesa por rios já dantes navegados: promoção, difusão e projeção de todos", disponível em www.ipol. org.br conseguia manifestar isso. A Licenciatura trouxe resposta a isso. (...) Essa para mim proporciona de a gente engrandecer, para que nós possamos realmente trabalhar voltado para a nossa realidade com as nossas crianças que são o futuro, o amanhã. Acredito que todos os professores que estão aqui, como alunos hoje na Licenciatura, eles têm o mesmo objetivo. 
Claro, alguns estão com dificuldade, mas são quatro anos de faculdade, com certeza no final dos quatro anos, nós vamos ter uma visão mais clara, e, com certeza, a educação que nós queremos vai melhorar muito a vida no Rio Negro. Eu tenho toda certeza disso... eu estou torcendo para que dê certo."

Concluindo, a experiência da Licenciatura da UFAM em São Gabriel da Cachoeira mostra que o Ensino via Pesquisa é o método utilizado no Ensino Superior como uma das estratégias que possibilitam a valorização da diversidade cultural elinguística intra-nacional, no âmbito dos povos originários. Mas a utilidade de tal metodologia não se restringe ao Ensino Superior, tampouco à diversidade intra-nacional, nem aos grupos indígenas. A diversidade inter-nações também é reconhecida e valorizada pelo Ensino via Pesquisa na Educação Básica no contexto fronteiriço pelo Projeto Escolas Interculturais Bilíngues de Fronteira do MERCOSUL.

\section{Estudo de Caso: o Ensino via Pesquisa para a Diversidade Latino-Americana Inter-Nacional no Projeto Escolas Interculturais Bilíngues de Fronteira do MERCOSUL}

O Projeto Escolas Interculturais Bilíngues de Fronteira inicia suas atividades pedagógicas em 2005 instituído por um Acordo Bilateral, assinado em 2004, entre os ministérios da educação de Brasil e Argentina. Em junho de 2006, o PEIBF entra para a pauta do Setor Educacional do MERCOSUL, passando, então, a constituir-se como um projeto multilateral. Em 2009, outros países do bloco (Uruguai, Paraguai e Venezuela) iniciam as atividades do projeto em escolas de fronteira.

Quanto ao funcionamento, o projeto trabalha a partir do intercâmbio docente, ou seja, duas vezes por semana as professoras brasileiras trocam de lugar com as professoras das escolas do outro lado da fronteira e ministram suas aulas em português para as crianças argentinas, por exemplo. Concomitante com a ida da professora brasileira, ocorre a vinda das professoras dos outros países que ministram suas aulas em espanhol para os alunos brasileiros. Sobre essa forma de funcionamento, o Documento-Base do PEIBF demonstra a utilidade da mesma na vivência da interculturalidade e do bilinguismo por parte dos docentes do projeto.

A unidade básica de trabalho, portanto, é o par de 'escolas-espelho', que atuam juntas formando uma unidade operacional e somando seus esforços na construção da educação bilíngue e intercultural. Esta forma permite aos docentes dos países envolvidos vivenciarem eles mesmos, na sua atuação e nas suas rotinas semanais, práticas de bilinguismo e de interculturalidade semelhantes às que querem construir com os alunos, na medida 
em que se expõem à vivência com seus colegas do outro país e com as crianças das várias séries com as quais atuam (MECyT \& MEC, 2008, p. 22).

O Projeto Escolas Interculturais Bilíngues de Fronteira (PEIBF) prevê, ainda, o desenvolvimento de um modelo comum de educação bilíngue e intercultural para a área de fronteira do MERCOSUL, conforme explicita o subtítulo do Documento-Base do Projeto escrito em 2006 e atualizado em 2008: Programa Escolas Bilingues de Fronteira - Modelo de ensino comum em escolas de zona de fronteira, a partir do desenvolvimento de um programa para a educação intercultural, com ênfase no ensino do português e do espanhol. Para se alcançar essa meta, durante a Primeira Reunião Técnica Bilateral, que ocorreu em Buenos Aires em dezembro de 2004, a metodologia de Ensino via Projetos de Aprendizagem ${ }^{4}$ é citada como

(...) uma solução para a necessidade de conteúdos compartilhados. Nesta visão educacional, o professor parte do interesse dos alunos, que constroem e executam projetos de pesquisa. Como os projetos são variados, a base curricular comum se refere muito mais aos processos de intelectualização dos alunos e ao modo como tratam dos objetos de conhecimento (OLIVEIRA, 2004 apud THOMAZ, 2010. p.19).

Durante a Segunda Reunião Técnica Bilateral, em Brasília em junho de 2005, chega-se a um acordo sobre o método a ser adotado no Projeto Escolas Interculturais Bilíngues de Fronteira do MERCOSUL. Por se tratar de um método não usual em contextos escolares, a reflexão sobre como instrumentalizar professores que atuam nas escolas do PEIBF e que nunca haviam trabalhado com o Ensino via Pesquisa leva a questão para os cursos universitários de formação docente, gerando o questionamento sobre se a utilização do Ensino via Pesquisa no processo de formação dos futuros professores que atuarão com essa metodologia traz benefícios. A universidade precisa ser repensada para a formação de professores gabaritados a atuar nas escolas do PEIBF?

Se há um projeto em vigor que prevê a construção de um modelo de ensino comum para a zona fronteiriça entre os países do MERCOSUL e se há indicativos do Setor Educacional do MERCOSUL para o reconhecimento, mobilidade e cooperação inter-institucional entre as universidade do bloco, seguindo os passos iniciais do Processo de Bolonha que prepara as universidades europeias para a integração e internacionalização de suas instituições de ensino superior, faria sentido repensar o papel das universidades para a formação de professores gabaritados a

4 Essa metodologia corresponde ao "Ensino via Pesquisa" ou "Aprendizado por problemas". atuar com a diversidade cultural e linguística latino-americana?

Para responder a essas questões é preciso considerar, então, a inserção do PEIBF, projeto multinacional, no plano de integração dos sistemas de ensino no bloco mercosulista e latino-americano. 


\section{Repensando a universidade}

O Projeto Escolas Interculturais Bilíngues de Fronteira insere-se, portanto, em uma série de políticas mercosulistas voltadas para a integração educacional. Essas políticas, como não poderia deixar de ser, abrangem também a integração dos sistemas de Ensino Superior e relacionam-se com a reestruturação geopolítica mundial em blocos regionais. Assim, a reflexão sobre a necessidade de se repensar a universidade frente à diversidade latino-americana se faz imperativa.

Em Por uma outra Globalização, Milton Santos (2000, p.24) afirma que "o desenvolvimento da história vai a par com o desenvolvimento das técnicas". E mais a frente, explicita que, nos tempos atuais, o que é representativo do sistema de técnicas é a chegada das técnicas da informação, através da internet, cibernética e eletrônica. Segundo o autor, pela primeira vez na história da humanidade, um conjunto de técnicas "envolve o planeta como um todo". São os tempos da Globalização.

Em consonância com a afirmação de Milton Santos e analisando a posição da educação superior no contexto histórico da Globalização, Dias Sobrinho (2005, p.48) parte da revolução tecnológica iniciada na década de 1970 na Califórnia para esclarecer por que "a educação superior tem centralidade no capitalismo reestruturado da era global." Para o autor, a causa geradora desta centralidade é o fato de o principal fator impulsor da reestruturação do capitalismo global ser a revolução das tecnologias da informação ocasionando "a passagem do valor econômico do material para o imaterial. O objeto físico perde valor ante o capital intelectual, dada a capacidade de este produzir riquezas". É o capital intelectual, agora, o maior gerador de riquezas, e não mais a indústria. E a instituição responsável pelo desenvolvimento deste tão valorizado capital é a universidade.

Esse novo valor agregado à Educação Superior, o valor econômico, além de atribuir a esse nível de educação uma posição central no mundo global, também impõe a universidade um dualismo funcional e conceitual.

É francamente diferente tratar a produção, a aquisição e a aplicação de conhecimento como um bem público e inegociável ou, por outro lado, como uma mercadoria. As diferenças de uma e outra concepção interferem efetivamente na produção, na distribuição, na aprendizagem, nos usos e nas finalidades dos conhecimentos (DIAS SOBRINHO, 2005, p.84).

De um lado, tem-se a Educação Superior concebida como bem público; do outro, como mercadoria. Como bem público, a educação superior deve difundir os conhecimentos em prol do desenvolvimento social. Como mercadoria, a educação superior deve ser adquirida por indivíduos interessados no desenvolvimento da competitividade pessoal. Nessa dualidade, ou nessa 
encruzilhada imposta à educação, em especial à Educação Superior, pelo capitalismo global, a educação "ou contribui para a reprodução do capital e sua barbárie ou para a construção de uma nova e superior forma de sociabilidade" (TONET, 2004, p.1).

Entendida como mercadoria no mundo capitalista devido ao valor econômico a ela atribuído, a demanda pela Educação Superior aumenta. Tanto mais aumenta essa demanda quanto mais se aumenta o valor agregado à Educação Superior. A impossibilidade de atendimento dessa demanda por parte do poder público favorece o aparecimento de novos tipos de provedores, como as universidades coorporativas, e de modalidades novas de instituições, a exemplo das virtuais. Assim, cresce a demanda pela Educação Superior, e cresce também a oferta da mesma. O ensino superior se adapta às novas exigências, e a competitividade entre instituições passa a ser fato. Essa competitividade baseia-se em uma só questão: ser a instituição que mais "vende" educação superior, ganhando, assim, a luta da concorrência.

Contudo, a competitividade não atinge somente o plano interinstitucional. Essa se faz sentir também em um plano supra-institucional e, mais, supranacional. Surge, então, em 1999, a Declaração de Bolonha com "o objetivo de elevar a competitividade internacional do sistema europeu do Ensino Superior". Trata-se, agora, da competitividade entre países ou grupo de países.

A Declaração de Bolonha ratifica o compromisso da Declaração de Sorbonne/1998 para a "criação de um espaço europeu do ensino superior". A partir dessas e de posteriores declarações firmadas ${ }^{5}$ surge um movimento que se convencionou chamar de Processo de Bolonha.

O Processo de Bolonha, nome do movimento de reforma e integração da educação superior na Europa, é o conjunto dos eventos relativos às medidas de implementação dos princípios da reunião havida em Bolonha em 1999 com a finalidade de construir um espaço europeu de educação superior até o ano 2010, cujos objetivos fundamentais encetam, principalmente, para a competitividade do Sistema Europeu de Ensino Superior frente a outras regiões e para a mobilidade e o emprego no Espaço Europeu, com vistas a harmonizar os sistemas universitários europeus, de modo a equiparar os graus, diplomas, títulos universitários, currículos acadêmicos, e adotar programas de formação contínua reconhecíveis por todos os Estados membros da União Europeia (AZEVEDO, 2006, p.1).

Se a consolidação da União Européia foi essencial para a iniciação do processo visando à internacionalização e integração do sistema de Educação Superior da Europa, a falta de um bloco regional coeso na América Latina caracteriza-se como um entrave para uma maior cooperação regional. "NAFTA, MERCOSUL,

5 Praga/2001, Ber$\mathrm{lim} / 2003$, Bergen/2005.
ALCA constituem tentativas de integração comercial que ainda não se consolidaram". (DIAS SOBRINHO, 2005, p. 211) Contudo, 
essas tentativas, se ainda não consolidadas, projetam, devido aos acordos já firmados relativos à Educação Superior, um caminho já iniciado em outras regiões do globo: o da internacionalização e integração dos sistemas de educação superior.

Dinamizadores de reformas visando à internacionalização e integração dos sistemas de educação superior em seus respectivos blocos regionais, o Processo de Bolonha na Europa e a Comissão Regional Coordenadora de Educação Superior do MERCOSUL têm trilhado caminhos parecidos. Embora, atrasado no plano temporal se comparado à União Europeia, o MERCOSUL já iniciou seu processo de internacionalização e integração dos sistemas de educação superior dos países membros.

Primeiramente, o MERCOSUL, pelo Setor Educacional, reconhece a importância da criação de um espaço acadêmico regional para o processo de integração:

En el ámbito de la educación superior, la conformación de un espacio académico regional, el mejoramiento de su calidad y la formación de recursos humanos constituyen el elementos sustanciales para estimular el proceso de integración (SEM, La Educación Superior en el Sector Educativo del Mercosur).

Mais tarde, na XXXI Reunião dos Ministros da Educação dos Países do MERCOSUL, realizada em novembro de 2006, oito ministros de Estados Membros ou Estados Associados do MERCOSUL "aprovaram a criação de um grupo de alto nível com o objetivo de elaborar o projeto de um espaço regional de educação superior do MERCOSUL". Sarti $(2008$, p. 7) retrata a esperança e a frustração deste projeto:

Até há pouco tempo, circulava no meio acadêmico a notícia da possível criação de uma Universidade do Mercosul. Contudo, a despeito de muitas tratativas, os governos dos países membros não chegaram a encontrar a fórmula operacional que, a curto prazo, concretizasse a idéia de uma instituição supra-nacional.

A criação da Universidade do MERCOSUL ainda não se concretizou, porém os indicativos para a integração dos sistemas de Educação Superior e da educação em zona fronteiriça são expressivos. Para dar conta da diversidade cultural e linguística latino-americana, as universidades teriam de se reposicionar de modo a oferecer a educação superior como bem público, e não como mercadoria, e como direito humano, e não como dever descaracterizador e inferiorizante.

Por objetivar a valorização da diversidade, possibilitada pelo trabalho educativo com foco nos interesses dos diversos grupos de alunos, o Ensino via Pesquisa exerce função essencial no reposicionamento das universidades latino-americanas frente à diversidade do bloco. Quando estudantes de nacionalidades distintas puderem estudar indistintamente em qualquer universidade da América Latina, quem determinará o que e como eles deverão 
aprender? Se a integração dos sistemas de Educação Superior na América Latina tiver como visão a valorização da diversidade regional e não a mercantilização do ensino, nenhum propositor de métodos e conteúdos para os cursos universitários será tão adequado quanto os próprios diversos alunos.

E por ser o método de ensino adotado pelo Projeto Escolas Interculturais Bilíngues de Fronteira do MERCOSUL, embrião de um modelo comum de ensino para a zona fronteiriça, a função do Ensino via Pesquisa como método de ensino para a formação dos professores na América Latina também se faz relevante. Se os professores do PEIBF são formadores para a diversidade cultural e linguística, como se formarão esses formadores? Como atestar a necessidade da valorização da diversidade cultural e linguística a não ser atestando-a na prática? Paulo Freire parecia já prever esses questionamentos atuais quando discorria sobre a coerência da prática docente, sobre a indissociabilidade entre pesquisa e ensino e sobre o saber de "experiência feito" dos alunos.

Não há ensino sem pesquisa e pesquisa sem ensino. Esses que-fazeres se encontram um no corpo do outro. Enquanto ensino, continuo buscando, reprocurando. Ensino porque busco, porque indaguei, porque indago e me indago. Pesquiso para constatar, constatando, intervenho, intervindo, educo e me educo. Pesquiso para conhecer o que ainda não conheço e comunicar ou anunciar a novidade. Não posso ser professor se não percebo cada vez melhor que, por não poder ser neutra, minha prática exige de mim uma definição. Uma tomada de posição. Decisão. Ruptura. Exige de mim que escolha entre isto e aquilo. (...) Sou professor a favor da luta constante contra qualquer forma de discriminação, contra a dominação econômica dos indivíduos ou das classes sociais. Sou professor contra a ordem capitalista vigente que inventou esta aberração: a miséria na fartura. Sou professor a favor da esperança que me anima apesar de tudo. Sou professor contra o desengano que me consome e imobiliza. Sou professor a favor da boniteza da minha própria prática, boniteza que dela some se não cuido do saber que devo ensinar, se não brigo por este saber, se não luto pelas condições materiais necessárias sem as quais meu corpo, descuidado, corre o risco de se amofinar e de já não ser o testemunho que deve ser de lutador pertinaz, que cansa mas não desiste. Boniteza que dela se esvai de minha prática se, cheio de mim mesmo, arrogante e desdenhoso dos alunos, não canso de me admirar. Assim como não posso ser professor sem me achar capacitado para ensinar certo e bem os conteúdos de minha disciplina não posso, por outro lado, reduzir minha prática docente ao puro ensino daqueles conteúdos. Esse é um momento apenas de minha atividade pedagógica. Tão importante quanto ele, o ensino dos conteúdos, é o meu testemunho ético ao ensiná-lo. É a decência com que o faço. É a preparação científica revelada sem arrogância, pelo contrário, com humildade. É o respeito jamais negado ao educando, a seu saber de "experiência feito" que busco superar com ele. Tão importante quanto o ensino dos conteúdos é a minha coerência 
em classe. A coerência entre o que digo, o que escrevo e o que faço." (FREIRE, 1996, p. 115).

\section{Abstract}

To rethink the university facing to the cultural and linguistic diversity present in Latin American countries, we must consider not only intra-

-national cases, but also the diversity between the countries themselves. That need arises from the establishment, by MERCOSUL, of some integration politics facing the education sector, covering both the Basic Education and Higher Education. Thus, the MERCOSUR Frontier Intercultural Bilingual Schools Project (PEIBF) and the thematic blocks of the Education Sector of MERCOSUR for Higher Education, namely, recognition, mobility and Inter-institutional cooperation, present themselves as instigators of reflections on how to cover classroom diversity in Latin American educational institutions of member countries. If the requirement of consideration is put, the way Education can work with and for the cultural and linguistic diversity, both in the intra and the inter-national cases, is still being defined. One of those ways is Teaching through Research. But why the Teaching through Research can be considered one of the instruments for the redefinition of the university and schools of the twenty-first century inserting them in a framework of valuing cultural and linguistic diversity? Aiming to answer this question, the work was organized to present the method "Teaching through Research" to then present two contexts in which it is adopted. One of these contexts uses the Teaching through Research for intra-national Latin American diversity, that of the native peoples. The other context encompasses the inter-national Latin American diversity, that between the MERCOSUR countries.

Keywords: Teaching through Research; MERCOSUR Frontier Intercultural Bilingual Schools Project; Indigenous Graduation; Cultural and Linguistic Diversity; Linguistic Politics.

\section{REFERÊNCIAS}

AZEVEDO, M. L. N. A Integração dos Sistemas de Educação Superior na Europa: de Roma a Bolonha ou da integração econômica à 
integração acadêmica. In: 29a Reunião Anual da ANPEd, 2006, Caxambu (MG). Educação, Cultura e Conhecimento na Contemporaneidade: desafios e compromissos. Rio de Janeiro : ANPEd, 2006.

Declaração de Bolonha. Disponível em:

http://www.aauab.pt/bolonha/declaracaobolonha.pdf

DIAS SOBRINHO, J. Dilemas da Educação Superior no Mundo Globalizado. Sociedade do conhecimento ou economia do conhecimento? São Paulo: Casa do Psicólogo, 2005.

FREIRE, P. Pedagogia da Autonomia: saberes necessários à prática educativa. São Paulo: Paz e Terra, 1996.

MECyT \& MEC. Programa Escolas Bilingues de Fronteira. Buenos Aires e Brasília: 2008.

OLIVEIRA, G.M. (org.) Interesse, pesquisa e ensino: uma equação para a Educação Escolar no Brasil. Florianópolis: IPOL e SME, 2004.

SANTOS, B. de S. La reinvención del Estado y el Estado plurinacional. In: Revista OSAL - Observatório Social da América Latina. Ano VIII, n²2. Buenos Aires: CLACSO, 2007. Disponível em:

http://bibliotecavirtual.clacso.org.ar/ar/libros/osal/osal22/ D22SousaSantos.pdf

SANTOS, M. Por uma outra globalização. Rio de Janeiro: Record, 2000.

SARTI, I. UNILA: a ousadia de um sonho. Jornal da Ciência, Rio de Janeiro, 02 mai. 2008, p. 7.

SEM. Setor Educacional do Mercosul. ATA XXXI Reunião dos Ministros da Educação dos Países do Mercosul. Disponível em:

http://www.sic.inep.gov.br/index.php?option=com_docman\&task= cat_view\&gid= $=48 \&$ Itemid $=32$

SEM. Setor Educacional do Mercosul. La Educación Superior en el Sector Educativo del Mercosur. Disponível em:

http://www.sic.inep.gov.br/index.php?option=com_content\&task=blogcategory\&id=19\&Itemid=37

THOMAZ, K.M. Política Linguística para a Integração: a experiência das Escolas Interculturais Blíngues de Fronteira do MERCOSUL. Cascavel: UNIOESTE, 2010.

TONET, I. A educação numa encruzilhada. MENEZES, Ana Maria D.; FIGUEIREDO, Fábio F. (org.). In: Trabalho, sociabilidade e educação. Fortaleza: Editora UFC, 2004, v. 14, pp. 201-219. 